\title{
NEURAL NETWORK AND MULTIPLE REGRESSION MODELS FOR ESTIMATION OF PRODUCTION RATES IN EXCAVATION OPERATIONS *
}

EIJEST

\author{
Emad E. Elbeltagi ${ }^{1}$, Hossam H. Mohamed ${ }^{2}$, Dhaheer A. Thabet ${ }^{2 * *}$ \\ ${ }^{1}$ Structural Eng. Dept., Mansoura Univ., Egypt. \\ ${ }^{2}$ Construction and Utilities Eng. Dept., Zagazig Univ., Egypt.
}

\begin{abstract}
Production rate estimation is one of the most frequently discussed topics in construction industry. Production rates of excavation operation in building construction are affected by several factors. Among these factors are: hauling distance, loading area layout, dumping area layout, pile foundation, excavator bucket capacity, size and number of hauling units. Consequently, estimation accuracy here is challenged when the effects of these multiple factors are simultaneously considered. In this paper, a comprehensive review of literature and interview with project managers were performed to identify the most significant factors affecting the production rates excavation operations. Sixteen factors were identified as the most significant factors affect the production rates of such operations. These factors were classified into three categories, namely: 1) Job - Site Conditions, 2) Equipment Characteristics, 3) Management Conditions. The objective in this paper is the development of a suitable tool that can be effectively used to predict the production rates of the excavation operation in building construction projects. For this purpose, field observations were conducted to collect realistic production rates over a period of twelve months (12/7/2009 to 17/7/2010) in the city of Alexandria (Egypt). Eighty-five actual case studies taken from seventeen building projects were used as raw data to develop the proposed neural network (NNM) and multiple regression (MRM) models. These data were randomly divided into two groups: (1) training data (75 actual production rates), (2) validating data (10 actual production rates). In conclusion, comparison between the predictive capabilities of both the best NNM and the best MRM indicates that the NNM outperforms the MRM.
\end{abstract}

KEY WORDS: Production rates; Excavation operation; Neural network; Regression.

\section{RESEAU NEURONAL ET DE MODELES DE REGRESSION MULTIPLE POUR L'ESTIMATION DES TAUX DE PRODUCTION DANS LES OPÉRATIONS DE EXCAVATION}

\section{RÉSUMÉ}

Estimation du taux de production est l'un des sujets les plus fréquemment discutés dans l'industrie de la construction. Les taux de production de l'opération de fouilles dans le bâtiment sont affectés par plusieurs facteurs. Parmi ces facteurs sont: le transport à distance, le chargement structure de l'espace, le dumping mise en espace, fondation sur pieux, la capacité de godet de l'excavatrice, la taille et le nombre d'unités de débardage. Par conséquent, sa précision d'estimation pourrait être contestée lorsque les effets de ces multiples facteurs sont considérés simultanément. Dans ce document de recherche à un examen complet de la littérature et des entrevues avec des gestionnaires de projet ont été réalisées pour identifier les facteurs les plus importants qui affectent les taux de production de l'opération de fouilles. Seize facteurs ont été identifiés comme les facteurs les plus importants qui affectent les taux de production de l'opération d'excavation. Ces facteurs ont été classés en trois catégories, à savoir: 1) Job - Conditions du site, 2) caractéristiques des équipements, 3) Condition de gestion. L'objectif de ce document de recherche est le développement d'un outil adapté qui peut être efficacement utilisé pour prédire le taux de production de l'opération d'excavation dans la construction de projets de construction. A cet effet, les observations de terrain ont été menées pour collecter des taux de production réalistes sur une période de douze mois (07/12/2009 au 17/7/2010), à Alexandrie - Egypte. Quatre-vingt-cinq études de cas réels tirés de dix-sept projets bâtiment construit à Alexandrie - Egypte ont été utilisées comme données brutes pour développer le modèle de réseau neuronal proposé (NNM) et le modèle de régression multiple $(\mathrm{MRM})$. Ces données ont été répartis aléatoirement en deux groupes: (1) les données d'entraînement (75 taux de production réels), (2) la validation des données (10 taux de production réels). En conclusion, la comparaison entre les capacités prédictives des deux meilleurs NNM et la meilleure MRM a indiqué que la NNM surperformé le MRM.

MOTS CLÉS: simulation, opération d'excavation, les rate de la production, le cost unitaire.

* Received: 12/7/2011, accepted: 11/9/2011 (Technical Paper)

** Contact author(dhaheer_abdelsamad@yahoo.com, +2 01281290 947) 


\section{INTRODUCTION}

Excavation operation is often one of the most important operations in any construction project in terms of its serious effect on both cost and time of these projects. Production rates estimation of excavation equipment generally based on the company's historical data and experts' opinion. In addition to these sources, production rates in handbooks and information from equipment suppliers are often used as references for estimation. The inaccuracy of production rates estimation is not only resulted from ineffective verification, but is also caused by the inconsistent consideration of the most important factors affecting the production rates of the excavation operation. Moreover, the accuracy of the production rates estimation in the planning phase could be challenged when the effect of multiple factors is considered simultaneously.

The duration of a construction project is usually determined by the clients at the design stage and is then documented in the bid documents. Contractors are usually under an obligation to evaluate the feasibility of the project duration before a contract has been awarded. However, time pressures typically do not allow contractors to perform this analysis. Further complicating the matter, clients frequently use inaccurate production rates to estimate construction time. Therefore, many projects are developed using unrealistic contract time duration.

Using inaccurate production rates to estimate construction time and cost has been recognized as a major source of bias in cost and time estimation. The only way to prevent inaccurate contract time estimation is to use realistic production rates. This research aims to develop NNM and MRM by using the realistic production rates to assist the planners and estimators to reduce the effort required for planning excavation operation as well as to improve the accuracy of production rates estimation.

\section{FACTORS AFFECTING PRODUCTION RATES OF EXCAVATION OPERATIONS}

In this paper a comprehensive review of literature and interview with project managers were performed to identify the most significant factors affecting the production rates of the excavation operation.
Chao and Skibniewski (1994) performed a case study in which a neural network was used to predict the productivity of an excavator. Flood and Christophilos $^{7}$ (1996) modeled earthmoving operations utilizing neural networks. Shi ${ }^{18}$ (1999) developed an artificial neural network for predicting earthmoving operations in a mining reclamation project. Smith ${ }^{19}$ (1999) used linear regression model to estimate the productivity of the earthmoving operations in highway projects. Edwards and Holt ${ }^{6}$ (2000) developed regression model to calculate the excavator productivity and output costs. Peurifoy et al. ${ }^{16}$ (2010) considered the shovel machine as a dependent unit in the excavation operation. They identified nine factors affected the production rate of the shovel. Jonasson et al. ${ }^{10}(2002)$ studied the productivity of earthwork for different types of advanced positioning systems. Tam et al. ${ }^{20}$ (2002) developed a quantitative model for predicting the production rate of excavator using artificial neural networks (ANN) to establish a higher precision model. Bhurisith and Touran ${ }^{4}$ (2002) conducted a case study with regard to obsolescence and equipment production rate and the ideal production rates of wheel type loaders, track-type loaders, scrapers, and crawler dozers. Hegazy and $\mathrm{Kassab}^{8}$ (2003) presented a simple and powerful approach for resource management and optimization in construction projects using a combination of flow chart-based simulation and genetic algorithms (GAs). Two examples were presented in this study to show the power and diversity of the proposed GA-optimized simulation planning approach: concrete-columns placing and earthmoving operation at Hong Kong International Airport. Marzouk and Moselhi ${ }^{11}$ (2003) presented a simulation engine, developed to model earthmoving operations. Marzouk and Moselhi ${ }^{12}$ (2004) presented a framework for optimizing earthmoving operations using computer simulation and genetic algorithms. Moselhi and Alshibani ${ }^{15}$ (2009) developed optimization model for earthmoving operation in heavy civil engineering projects.

Based on the above comprehensive review of literature and interview with project managers sixteen factors (Table 1) were identified as the most significant factors affecting the production rates of excavation operation. According to Table (1), such factors were classified into three categories. Such categories mainly include: Job- site Condition, Equipment Characteristics and Management Conditions. 
Table 1: Factors affecting production rates of excavation operations

\begin{tabular}{|c|c|c|c|}
\hline Category & Description & Factors included in Category & Symbol \\
\hline \multirow{7}{*}{ (1) } & \multirow{7}{*}{ Job-Site Conditions } & (1) Loading area layout & $\mathrm{X}_{1}$ \\
\hline & & (2) Dumping area layout & $\mathrm{X}_{2}$ \\
\hline & & (3) Type of soil & $X_{3}$ \\
\hline & & (4) Excavation depth & $\mathrm{X}_{4}$ \\
\hline & & (5) Haul distance & $\mathrm{X}_{5}$ \\
\hline & & (6) Pile foundation & $\mathrm{X}_{6}$ \\
\hline & & $\begin{array}{l}\text { Weather conditions: } \\
\text { (7) Temperature } \\
\text { (8) Relative humidity } \\
\text { (9) Rainfall }\end{array}$ & $\begin{array}{l}\mathrm{X}_{7} \\
\mathrm{X}_{8} \\
\mathrm{X}_{9} \\
\end{array}$ \\
\hline \multirow{4}{*}{ (2) } & \multirow{4}{*}{ Equipment Characteristics } & $\begin{array}{l}\text { (1) Excavator bucket capacity } \\
\text { (2) Maximum digging depth of excavator }\end{array}$ & $\begin{array}{l}X_{10} \\
X_{11}\end{array}$ \\
\hline & & (3) Swing angle & $\mathrm{X}_{12}$ \\
\hline & & (4) Size of hauling units & $\mathrm{X}_{13}$ \\
\hline & & (5) Number of hauling units & $\mathrm{X}_{14}$ \\
\hline \multirow{2}{*}{ (3) } & \multirow{2}{*}{ Management Conditions } & (1) Efficiency of supervision & $\mathrm{X}_{15}$ \\
\hline & & (2) Operator skill & $\mathrm{X}_{16}$ \\
\hline
\end{tabular}

\section{DATA COLLECTION}

In this research, the production rates of the excavation operation for building foundation will be defined as the total amount of material loaded by the excavator to the trucks, the trucks once loaded, haul to the dump area, dump the load and return to the queue in a unit time such as a minute or an hour. A field observation is conducted by the researcher over a period of twelve months (12/7/2009 to 17/7/2010) in the city of Alexandria (Egypt). A data collection form was designed for collecting the required data. A total number of eighty-five actual case studies were collected from seventeen construction projects. These data were divided into two groups randomly: (1) training data (75 actual production rates), (2) validating data (10 actual production rates). The collected data of these cases mainly include the production rates of excavation operation as well as the different factors affecting such production. For further information, the reader is referred to Thabet ${ }^{21}$ (2011).

\section{ARCHITECTURE OF NEURAL NETWORK MODEL}

The sixteen factors that listed in Table (1) and the production rates are used as input and output neurons of the back-propagation neural network, respectively. To determine the number of hidden layers, Bailey and Thompson ${ }^{2}$ (1990) suggested, as a rule of thumb, start with one hidden layer and add more as long as the performance of the network is improved. The size of the hidden layer (number of hidden neurons) can be specified by using a number of heuristics including: 1) Bailey and Thompson ${ }^{2}$ (1990) suggested the number of neurons to be around $75 \%$ of the size of the input layer, 2) BrainMaker Professional user's guide ${ }^{3}$ (1998) suggested that the number of neurons in hidden layer to be as per the following formula:

$$
\text { No. Of Neourons }=\text { Inputs }+ \text { Outputs } / 2 \ldots
$$

All the above recommendations are considered as a first step to develop the present model. Moreover, Moselhi et al. ${ }^{14}$ (1991) advised that the proper number is determined by the experimentations. Therefore, for verifying this work, the traditional trial and error process was performed in order to reach the best possible 


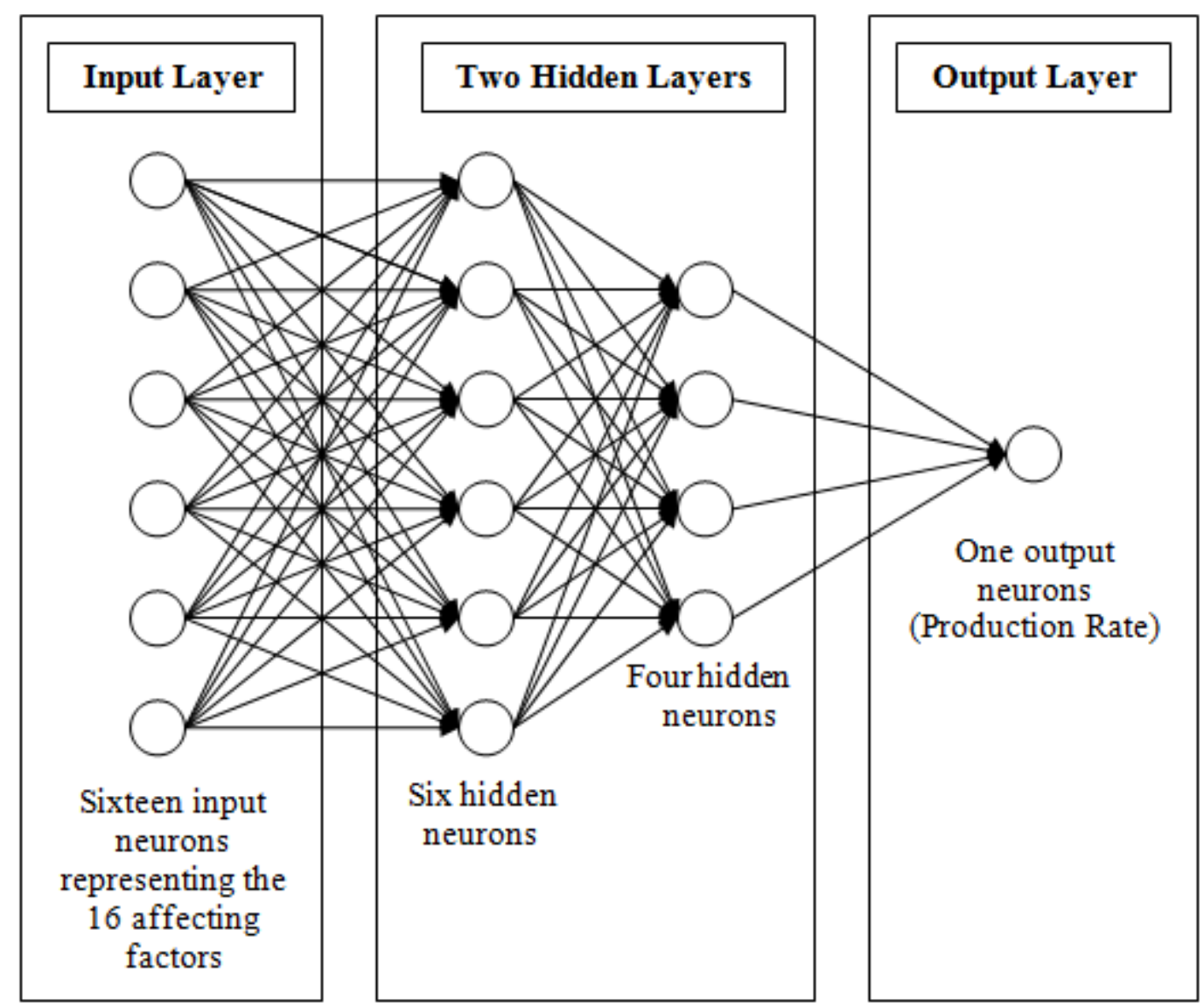

Fig. 1. Architecture of neural network model

network that gave the minimum error during training and the best results when applied to the validation set. In this research, two hidden layers (6 hidden neurons in the first layer and 4 hidden neurons in the second layer) were found to be capable of achieving the best results for predicting the production rates of excavation operation. The architecture of the best NNM is shown in Fig. (1).

\subsection{Training and Testing Neural Network Model}

Training is required to continuously adjust the connection weights until they reach values that allow the artificial neural network to predict outputs that are very close to the actual outputs while being able to generalize well on new cases (Hegazy et al. ${ }^{9}(1994)$ ).

In order to develop the NNM BrainMaker Professional software package 3.75 (2001) has been used for its ease of use, speed of training, and for its host of neural network architectures including back propagation with flexible user selection of training parameters. BrainMaker Professional 3.75 includes a simplified set of procedures for building and executing complete and powerful neural networks application. The user has the ability to specify the learning rate, tolerance, activation functions, number of hidden layer and number of hidden neurons. It also has multiple criteria for stopping training in addition to different methods for handling missing data, pattern selection and viewing weight and neuron values during training (BrainMaker Professional- User's Guide and Reference Manual $^{3}$ (1998)). During training, a neural network is presented with the data many thousands of times (called cycles or epochs). After each cycle, the error between the neural network predicted outputs and the actual outputs are propagated backwards to adjust the weights in a manner that is mathematically guaranteed to 




Fig. 2. Statistical graph of training results

Table 2: NNM architecture, parameters and training results

\begin{tabular}{|c|c|c|c|c|c|c|c|}
\hline \multicolumn{4}{|c|}{ NNM Architecture } & \multirow{2}{*}{$\begin{array}{c}\text { Learning } \\
\text { Rate }\end{array}$} & \multirow[b]{2}{*}{ Tolerance } & \multirow{2}{*}{$\begin{array}{l}\text { Transfer } \\
\text { Function }\end{array}$} & \multirow{2}{*}{$\begin{array}{l}\text { RMS } \\
\text { Error }\end{array}$} \\
\hline $\begin{array}{l}\text { Input } \\
\text { layer }\end{array}$ & $\begin{array}{c}\text { First } \\
\text { Hidden } \\
\text { Layer } \\
\end{array}$ & $\begin{array}{c}\text { Second } \\
\text { Hidden Layer }\end{array}$ & $\begin{array}{c}\text { Output } \\
\text { Layer }\end{array}$ & & & & \\
\hline 16 & 6 & 4 & 1 & 0.1 & 0.1 & Sigmoid & $6.08 \%$ \\
\hline
\end{tabular}

converge (Rumelhart et al. ${ }^{17}$ (1986)). Several training experiments were conducted to arrive at the best training model.

In these experiments, parameters of the networks structure such as the number of hidden layers, the number of hidden neurons, learning rate, tolerance, and transfer function such as sigmoid function, linear function, and other functions available on the software were changed and the best results were documented.

After training the network, the user can evaluate the training and testing processes by using the training and testing statistical files. The best model was selected based on reaching acceptable minimum values of the root mean square error (RMS Error). The collected data were divided into two sections, training data $(90$ $\%$ of the training data set) and testing data (10 $\%$ of the training data set). The training RMS Error for the network is the average of the root square of the difference between the actual and predicted outputs for the training data set. The testing RMS Error for the network is the average of the root square of the difference between the actual and predicted outputs for the testing data.

The mean squared error equation is:

$$
\text { RMS Error }=\frac{1}{\mathrm{~N}} * \sqrt{\Sigma(\mathrm{A}-\mathrm{P})^{2}}
$$

Where RMS Error $=$ root mean square error; $\mathrm{N}$ $=$ number of cases; $\mathrm{A}=$ actual production rate; $\mathrm{P}$ $=$ predicted production rate.

During training, the RMS Error between the actual and predicted values for the production rates was plotted as shown in Fig. (2). It was clear that the error decreased as the number of runs increase and then become stable. The network used as the best model for this research that trained and tested successfully has a minimum RMS Error of approximately $6.08 \%$. The network stabilized at this error rate and training was stopped at 4924 runs. The architec- 
Table 3: NNM validation results

\begin{tabular}{|c|c|c|c|}
\hline No. of Cases & Actual Production Rates & $\begin{array}{c}\text { Predicted Production } \\
\text { Rates }\end{array}$ & Error \\
\hline 1 & 375 & 363.84 & 11.16 \\
\hline 2 & 445 & 409.83 & 35.17 \\
\hline 3 & 338 & 363.17 & -25.17 \\
\hline 4 & 454 & 445.37 & 8.63 \\
\hline 5 & 1067 & 1020.7 & 46.3 \\
\hline 6 & 492 & 487.14 & 4.86 \\
\hline 7 & 1040 & 1044.3 & -4.3 \\
\hline 8 & 430 & 428.49 & 1.51 \\
\hline 9 & 368 & 405.38 & -37.38 \\
\hline 10 & 694 & 725.97 & -31.97 \\
\hline \multicolumn{4}{|c|}{$\begin{array}{c}\text { RMS Error }=8.17 \% \\
\text { MAPE }=4.11 \% \\
R^{2}=0.991\end{array}$} \\
\hline
\end{tabular}

ture, parameters and training results of the best NNM are tabulated in Table (2).

\subsection{Neural Network Model Validation}

Once the network was trained and a satisfactory error level was achieved, the validation data that had not been presented to the network during training were used to check how well the trained model predicts the production rates that it has never seen before. Three evaluation parameters were used as a basis for evaluating the performance of the trained neural network model: (1) Root mean square error (RMS Error); (2) Mean absolute percentage error (MAPE); (3) adjusted square multiple $\mathrm{R}\left(\mathrm{R}^{2}\right)$. Mathematically, these parameters are defined as follows:

RMS Error $=\frac{1}{\mathrm{~N}} * \sqrt{\Sigma(\mathrm{A}-\mathrm{P})^{2}}$

MAPE $=\frac{1}{\mathrm{~N}} * \Sigma(\mid(A-P) / A) \mid * 100$

$\mathrm{R}^{2}=\frac{\left[N * \sum(A P)-\left(\sum A\right) *\left(\sum P\right) \mathbb{1}^{2} \ldots \ldots \ldots \ldots(5)\right.}{\left[N * \sum\left(A^{2}\right)-\left(\sum A\right)^{2}\right] *\left[N * \sum\left(P^{2}\right)-\left(\sum P\right)^{2}\right]}$
Where $\mathrm{N}=$ number of cases; $\mathrm{A}=$ actual value; $\mathrm{P}=$ predicted value.

The results of the validation process were summarized in Table (3). As shown in Table (3), the RMS Error, MAPE and $\mathrm{R}^{2}$ were found to be $8.17 \%, 4.11 \%$ and 0.991 respectively. These results reveal that the developed model has excellent predictive capabilities.

\section{REGRESSION ANALYSIS}

Many problems in engineering and science involve exploring the relationships between two or more variables. Regression analysis is a statistical technique that is very useful for these types of problems (Montgomery and Runger ${ }^{13}(2010)$ ).

The multiple regression model (MRM) will be used to determine the statistical relationship between a response or dependent variable (e.g. actual production rate) and the explanatory variables or independent variables (e.g., excavator bucket capacity, haul distance, or truck capacity). The responses to the regression model are what the planning engineer ultimately wants to estimate. 
Table 4: MRM 1- using stepwise technique

\begin{tabular}{|c|c|c|c|}
\hline \multicolumn{4}{|c|}{$\begin{array}{c}\text { Adjusted square multiple R }=\mathbf{0 . 9 6 2} \\
\boldsymbol{F} \text { ratio }=\mathbf{3 1 6 . 4 1 3}, \boldsymbol{P} \text { - value }=\mathbf{0 . 0 0}\end{array}$} \\
\hline Variables & Coefficients & $\boldsymbol{t}$-ratio & Partial $\boldsymbol{F}$ \\
\hline Constant & -667.668 & -7.970 & 0.000 \\
\hline $\begin{array}{c}\text { Excavator bucket } \\
\text { capacity }\end{array}$ & 251.693 & 2.082 & 0.041 \\
\hline Type of soil & 12.923 & 1.979 & 0.052 \\
\hline Haul distance & -61.161 & -8.534 & 0.000 \\
\hline Haul unit number & 94.435 & 9.515 & 0.000 \\
\hline Haul unit size & 68.885 & 9.263 & 0.000 \\
\hline Loading area layout & 39.351 & 3.368 & 0.001 \\
\hline
\end{tabular}

Table 5: MRM 2 - using backward technique

\begin{tabular}{|c|c|c|c|}
\hline \multicolumn{4}{|c|}{$\begin{array}{c}\text { Adjusted square multiple } \mathrm{R}=0.964 \\
F \text { ratio }=283.043, P \text { - value }=0.00\end{array}$} \\
\hline Variables & Coefficients & $t$-ratio & Partial $F$ \\
\hline Constant & -567.305 & -4.652 & 0.000 \\
\hline $\begin{array}{c}\text { Dumping area } \\
\text { layout }\end{array}$ & 48.811 & 4.002 & 0.000 \\
\hline Type of soil & 18.218 & 2.596 & 0.012 \\
\hline Haul distance & -65.581 & -9.803 & 0.000 \\
\hline Haul unit size & 68.784 & 9.349 & 0.000 \\
\hline Obstacles & -78.518 & -2.301 & 0.024 \\
\hline Haul unit number & 104.443 & 16.784 & 0.000 \\
\hline Loading area layout & 16.516 & 2.275 & 0.026 \\
\hline
\end{tabular}

The MRM is given by the equation:

$$
\begin{aligned}
& Y=\beta_{0}+\beta_{1} x_{1}+\beta_{2} x_{2}+\beta_{p} x_{p}+\varepsilon_{i} \\
& \quad i=1,2, \ldots n
\end{aligned}
$$

and assuming the following:

- $\mathrm{Yi}$ is the response that corresponds to the levels of the explanatory variables $x_{1}, x_{2}, \ldots, x_{\mathrm{p}}$ at the $i$ th observation.

- $\beta_{0}, \beta_{1}, \ldots, \beta_{p}$ are the coefficients in the linear relationship. For a single factor $(\mathrm{p}=1), \beta_{0}$ is the intercept, and $\beta 1$ is the slope of the straight line defined.

- $\varepsilon_{1}, \varepsilon_{2}, \ldots, \varepsilon_{n}$ are the errors that create scatter around the linear relationship at each of the $\mathrm{i}=1$ to $\mathrm{n}$ observations.

To make estimates of the coefficients in the regression model, the method of least squares is used for both its mathematical convenience and its ability to provide explicit expressions for these estimates $\left(\operatorname{Smith}^{19}(1999)\right)$. 
Table 6: MRM 3 - using forward technique

\begin{tabular}{|c|c|c|c|}
\hline \multicolumn{4}{|c|}{$\begin{array}{c}\text { Adjusted square multiple } \mathbf{R}=\mathbf{0 . 9 6 3} \\
\boldsymbol{F} \text { ratio }=\mathbf{2 8 8 . 1 0 7}, \boldsymbol{P} \text { - value }=\mathbf{0 . 0 0}\end{array}$} \\
\hline Variables & Coefficients & $\boldsymbol{t}$-ratio & Partial $\boldsymbol{F}$ \\
\hline Constant & -527.090 & -4.284 & 0.000 \\
\hline $\begin{array}{c}\text { Excavator bucket } \\
\text { capacity }\end{array}$ & 231.864 & 1.927 & 0.058 \\
\hline Type of soil & 17.509 & 2.462 & 0.016 \\
\hline Haul distance & -60.248 & -8.463 & 0.000 \\
\hline Obstacles & -69.10 & -1.547 & 0.127 \\
\hline Haul unit size & 87.296 & 8.042 & 0.000 \\
\hline Haul unit number & 62.528 & 7.416 & 0.000 \\
\hline Dump area layout & 46.895 & 3.736 & 0.000 \\
\hline
\end{tabular}

\subsection{Regression Model Development}

Various regression models for excavation operations were developed using statistical analysis techniques (stepwise, backward, and forward techniques). The SPSS 18 package, which was used to analyze the data and develop the models, provides the user with the ability to select one of the three different techniques.

The collected data set was divided randomly into two main groups: model developing (75 observations), and validation (10 observations) data sets. These data were organized and saved in Microsoft Excel spreadsheet. The SPSS 18 package is compatible with Microsoft Excel. Therefore, the data exported from Excel to SPSS using the file import option in SPSS.

For a model, that includes sixteen variables with the use of seventy-five case case studies:

$$
\mathrm{F}_{\text {critical }}=\mathrm{F}_{\alpha, \mathbf{p}-\mathbf{1}, \mathbf{n}-\mathbf{p}}=\mathrm{F}_{\mathbf{0 . 0 5}, \mathbf{1 6}, \mathbf{5 8}}=1.84 \ldots \ldots
$$

where $n=$ number of observations, which equal to eighty-five; $p=$ independent variables in the complete model, which equal to sixteen variables plus the constant (total 17). P-1= number of degree of freedom for the regression, $n-p=$ degree of freedom for the error.

Several modelling experiments took place; the three most suitable models are shown in Tables (4), (5) and (6).

Based on the statistical tests, it can be concluded that the regression model produced by using the backward technique is more useful in predicting the dependent variable (production rates) since it provided a better statistical diagnostics with regard to its F-ratio, t-ratio, Adjusted square multiple R. The Adjusted square multiple $\mathrm{R}=0.964$. This statement means that the model is able to explain $96.4 \%$ of the variability on the data. The tolerance is an indicator of multicollinearity, which inflates the variance of the least square estimators and possibly predictions made (Attalla et al. ${ }^{1}$ (2003)). The results that obtained from the statistical analysis indicated that all of the independent variables in model 2 have a tolerance $>0.1$, which indicated that multicollinearity does not exist among the independent variables (Attalla et al. ${ }^{1}$ (2003)).

The best model is given by the formula:

Production Rate $=-567.305+16.516 \boldsymbol{X}_{\boldsymbol{I}}+$ $48.811 \boldsymbol{X}_{2}+18.218 \boldsymbol{X}_{3}-65.581 \boldsymbol{X}_{5}-78.518 \boldsymbol{X}_{6}$ $+68.784 X_{13}+104.443 X_{14} \ldots \ldots \ldots \ldots \ldots$

\subsection{Regression Model Validation}

The data, which were provided in the ten validation sets, were applied to the equation (8). The model produced ten predicted values for the production rates of excavation operation. Three evaluation parameters were used as the basis for evaluating the performance of the MRM: (1) Root mean square error (RMS Error); (2) Mean absolute percentage error (MAPE); (3) adjusted square multiple $\mathrm{R}\left(\mathrm{R}^{2}\right)$.

The results of the validation were tabulated in Table (7). As shown in Table (7), the RMS Error, MAPE and $\mathrm{R}^{2}$ were found to be $10.98 \%, 5.66 \%$ and 0.986 respectively. These results reveal that the developed model has excellent predictive capabilities. 
Table 7: MRM validation results

\begin{tabular}{|c|c|c|c|}
\hline No. of Cases & Actual Production Rates & $\begin{array}{c}\text { Predicted Production } \\
\text { Rates }\end{array}$ & Error \\
\hline 1 & 375 & 352.06 & 22.94 \\
\hline 2 & 445 & 418.39 & 26.61 \\
\hline 3 & 338 & 324.72 & 13.28 \\
\hline 4 & 454 & 388.11 & 65.89 \\
\hline 5 & 1067 & 1038.15 & 28.85 \\
\hline 6 & 492 & 460.28 & 31.72 \\
\hline 7 & 1040 & 1096.72 & -56.72 \\
\hline 8 & 430 & 421.42 & 8.58 \\
\hline 9 & 368 & 388.11 & -20.11 \\
\hline 10 & 694 & 721.62 & -27.62 \\
\hline \multicolumn{4}{|c|}{$\begin{array}{c}\text { RMS Error }=10.98 \% \\
\text { MAPE }=5.66 \% \\
R^{2}=0.987\end{array}$} \\
\hline
\end{tabular}

\section{COMPARISON BETWEEN NEURAL NETWORK MODEL AND MULTIPLE REGRESSION MODEL}

The results (i.e. predicted values) obtained by using the best NNM were compared to those obtained by using the best MRM. Table (8) illustrates a comparison between the predictive capabilities of the best NNM versus the predictive capability of the best MRM.

This comparison was based on five evaluation parameters: 1) Mean absolute percentage error (MAPE), 2) Root mean square error (RMS Error), 3) Adjusted square multiple $\left.\mathrm{R}\left(\mathrm{R}^{2}\right), 4\right)$ Number of variables and 5) Number of cases within a specified percentage error.

As shown in Table (8), the results indicated that the NNM outperformed the MRM in the five evaluation parameters. The values of MAPE, RMSE, and $\mathrm{R}^{2}$ for the neural network model are $4.11 \%, 8.17 \%$ and 0.991 respectively, while the values of the same parameters, for the regression model, are $5.66 \%, 10.98 \%$ and 0.986 . In addition, the value of the number of variables indicated that the NNM was able to predicate the production rates by utilizing the sixteen variables, whereas the MRM utilized seven variables only. From a planner or user's point of view, the ability to use more variables in predicting the production rate of future projects may be advantageous. For the number of cases within a certain percentage of error range, the results of the fifth evaluation parameters indicated that there were no cases within $0 \%$ error for both models. However, there are more cases of NNM in the " $<5 \%$ " range of error. Finally, the comparison's results indicated that the NNM outperformed the MRM in these ranges of error.

Another useful comparison is to plot the prediction error (Actual-Predicted), for each case, for NNM and MRM. This comparison gives clear indication about the accuracy of each model. As shown in Fig. (3), the prediction error plot indicated that the NNM outperformed the MRM in five cases (1, 4, 6, 7 and 8 cases). The prediction error of these cases is close to 0 while the prediction error of the same cases, for the MRM, is not close to 0. Although the comparison between the values of the remaining five cases, cases 2, 3, 5, 9 and 10, indicates that the MRM outperformed the NNM, but the difference between these values is not large compared to the difference between the values of the previous five cases. In general, the prediction error plot indicates that the NNM outperformed the MRM. 
Table 8: Comparison between the NNM and MRM

\begin{tabular}{|c|c|c|c|c|c|c|c|c|c|c|c|c|c|c|c|c|c|c|c|c|c|c|c|}
\hline \multirow{3}{*}{$\begin{array}{l}\text { No. of } \\
\text { Cases }\end{array}$} & \multirow{3}{*}{$\begin{array}{l}\text { Actual } \\
\text { Value }\end{array}$} & \multicolumn{11}{|c|}{ Neural Network Model (NNM) } & \multicolumn{11}{|c|}{ Multiple Regression Model (MRM) } \\
\hline & & \multirow{2}{*}{$\begin{array}{l}\text { Predi } \\
\text { c-ted } \\
\text { Value }\end{array}$} & \multirow{2}{*}{ MAPE } & \multirow{2}{*}{ RMS } & \multirow{2}{*}{$\mathbf{R}^{2}$} & \multirow{2}{*}{$\begin{array}{l}\text { No. } \\
\text { of } \\
\text { Yari- } \\
\text { able }\end{array}$} & \multicolumn{6}{|c|}{$\begin{array}{c}\text { No. of Cases within } \\
\%\left[\begin{array}{c}\text { Actual-Predicted } p / \text { Actual }] \\
* 100\end{array}\right.\end{array}$} & \multirow{2}{*}{$\begin{array}{l}\text { Predic- } \\
\text { ted } \\
\text { Value }\end{array}$} & \multirow{2}{*}{ MAPE } & \multirow{2}{*}{ RMS } & \multirow{2}{*}{$\mathbf{R}^{2}$} & \multirow{2}{*}{\begin{tabular}{|c} 
No. \\
of \\
Vari- \\
bles
\end{tabular}} & \multicolumn{6}{|c|}{$\begin{array}{c}\text { No. of Cases within } \\
\%[(\mid \text { Actual-Predicted b/Actual }] \\
{ }_{1} 100\end{array}$} \\
\hline & & & & & & & $=$ & 5 & & $\begin{array}{l}5 \% \\
- \\
0 \%\end{array}$ & $\begin{array}{c}10 \% \\
- \\
20 \%\end{array}$ & $\begin{array}{c}20 \% \\
- \\
30 \%\end{array}$ & & & & & & & & $\begin{array}{c}< \\
5 \%\end{array}$ & $\begin{array}{c}5 \% \\
- \\
10 \%\end{array}$ & $\begin{array}{c}10 \% \\
- \\
20 \%\end{array}$ & $\begin{array}{c}20 \% \\
- \\
30 \%\end{array}$ \\
\hline 1 & 375 & 363.84 & \multirow{10}{*}{4.11} & \multirow{10}{*}{8.17} & \multirow{10}{*}{0.991} & \multirow{10}{*}{16} & \multirow{10}{*}{0} & \multirow{10}{*}{\multicolumn{2}{|c|}{7}} & \multirow{10}{*}{2} & \multirow{10}{*}{\multicolumn{2}{|c|}{1}} & 320.00 & \multirow{10}{*}{5.66} & \multirow{10}{*}{10.98} & \multirow{10}{*}{0.987} & \multirow{10}{*}{8} & \multirow{10}{*}{\multicolumn{2}{|c|}{0}} & & & & \\
\hline 2 & 445 & 409.83 & & & & & & & & & & & \begin{tabular}{|l}
421.74 \\
\end{tabular} & & & & & & & \multirow{8}{*}{3} & & & \\
\hline 3 & 338 & 363.17 & & & & & & & & & & & \begin{tabular}{|l}
326.39 \\
\end{tabular} & & & & & & & & & & \\
\hline 4 & 454 & 445.37 & & & & & & & & & & & 388.75 & & & & & & & & & & \\
\hline 5 & 1067 & 1020.7 & & & & & & & & & & & 1036.82 & & & & & & & & 5 & 2 & 0 \\
\hline 6 & 492 & 487.14 & & & & & & & & & & & \begin{tabular}{|l|l}
465.13 \\
\end{tabular} & & & & & & & & & & \\
\hline 7 & 1040 & 1044.3 & & & & & & & & & & & 1098.16 & & & & & & & & & & \\
\hline 8 & 430 & 428.49 & & & & & & & & & & & 387.10 & & & & & & & & & & \\
\hline 9 & 368 & 405.38 & & & & & & & & & & & 388.75 & & & & & & & & & & \\
\hline 10 & 694 & 725.97 & & & & & & & & & & & 723.48 & & & & & & & & & & \\
\hline
\end{tabular}



Fig. 3. Prediction errors of NNM and MRM

\section{CONCLUSIONS}

This paper attempts to develop two NNM and MRM that can be effectively used to predict the production rate of excavation operation. Based on a comprehensive review of literature and interviews with project managers sixteen factors were identified as the most significant factors affecting the production rates of excavation operation. A data collection form was designed for collecting the data required. A total number of eighty-five actual case studies were collected from seventeen construction projects. It can be concluded from the results of this study that:
1. The use of the NNM and MRM can help estimators to reduce the effort required for planning excavation operation as well as to improve the accuracy of production rate estimates to complete a project within budget and schedule.

2. The results indicate that both NNM and MRM can be effectively used to predict the production rates of excavation operation. However, the comparison between the predictive capabilities of the best NNM versus the predictive capabilities of the best MRM indicates that the NNM outperformed the MRM. 


\section{REFERENCES}

1. Attalla, M., Hegazy, T. and Haas, R., (2003), "Reconstruction of the building infrastructure: two performance prediction models." J. Constr. Eng. Manage., ASCE, Vol. 9 No 1, pp 26-34.

2. Bailey, D. and Thompson, D., (1990), "How to develop neural network applications." AI Expert, Vol. 5 No 6, pp 38-47.

3. BrainMaker Professional -User's Guide and Reference Manual, (1998), California Scientific Software.

4. Bhurisith, L., and Touran, A., (2002), "Case study of obsolescence and equipment productivity." J. Constr. Eng. Manage., ASCE, Vol. 128 No 4, pp 357-361.

5. Chao, L. and Skibniewski, M. J., (1994), "Estimating construction productivity: Neural network-based approach." J. Comput. Civ. Eng., ASCE, Vol. 8 No 2, pp 234-51.

6. Edwards, D. J and Holt, G. D., (2000), "ESTIVATE: a model for calculating excavator productivity and output costs." Engineering, Construction and Architectural Management, Vol.1, pp 52-62.

7. Flood, I. and Christophilos, P., (1996), "Modeling construction processes using artificial neural networks." Automation in construction., Vol. 4 No 4, pp 307-320.

8. Hegazy, T. and Kassab, M., (2003), "Resource optimization using combined simulation and genetic algorithms." J. Constr. Eng. Manage., ASCE, Vol. 129 No 6, pp 698-705.

9. Hegazy, T., Moselhi, O., and Fazio, P.,(1994), "A neural network approach for representing implicit knowledge in construction." Int. J. Constr. Inf. Technol., Vol.1 No. 3, pp 73-86.

10. Jonasson, S., Dunston, P. S., Ahmed, K., and Hamilton, J., (2002), "Factors in productivity and unit cost for advanced machine guidance.” J. Constr. Eng. Manage., ASCE, Vol. 128 No 5, pp 367-374.

11. Marzouk, M., and Moselhi, O., (2003), "Object-oriented simulation model for earthmoving operations." J. Constr. Eng. Manage., ASCE, Vol. 129 No 2, pp 173-181.
12. Marzouk, M. and Moselhi, O., (2004), "Fuzzy clustering model for estimating haulers' travel time.” J. Constr. Eng. Manage., ASCE, Vol. 130 No 6, pp 878-886.

13. Montgomery, D. C. and Runger, G. C., (2010), Applied statistics and probability for engineers. John Wiley \& Sons, Inc.

14. Moselhi, O., (1991), "Neural networks as tools in construction." J. Constr. Eng. Manage., ASCE, Vol. 117 No 4, pp 606-625.

15. Moselhi, O., and Alshibani, A., (2009), "optimization of earthmoving operations in heavy civil engineering projects." J. Constr. Eng. Manage., ASCE, Vol. 135 No 10, pp $948-954$.

16. Peurifoy, R. I. Schexnayder, C. J. and Shapira, A., (2010), Construction planning equipment and methods. Eighth Edition, Mc Graw-Hill Companies, Inc., New York.

17. Rumelhart, D., Hinton, G., and Williams, R., (1986), Parallel distributed processing. Vol.1. Foundations, MIT. Cambridge, Mass.

18. Shi, J. J., (1999), “A neural network based system for predicting earthmoving production." Constr. Manage. Econom., Vol. 17, pp 463-471.

19. Smith, S.D., (1999), "Earthmoving productivity estimation using linear regression techniques." J. Constr. Eng. Manage., ASCE, Vol. 125 No 3, pp 133-141.

20. Tam, C.M., Tong, T. K.L. and Tse, S.L., (2002), "Artificial neural networks model for predicting excavator productivity." J. Eng. Constr. Architect. Manage. Vol. 9 No 5-6, pp 446-452.

21. Thabet, D. A., (2012), "Predicting of production rate for excavation operation." $\mathrm{PhD}$ thesis, Faculty of Engineering, Zagazig University, Zagazig, Egypt. 